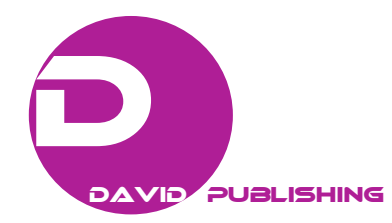

\title{
Transforming Strijp S: From Philips' Industrial Site to New Residential and Creative Area
}

\author{
Dimitra Babalis ${ }^{1}$ and Irene Curulli ${ }^{2}$ \\ 1. Department of Architecture, University of Florence, Florence 50132, Italy \\ 2. Department of the Built Environment, Eindhoven University of Technology, Eindhoven 5600 MB, the Netherlands
}

\begin{abstract}
In the contemporary city, the transformation of abandoned industrial landscapes offers great potential for experimentation and in creating new urban environments. Industrial heritage plays an essential role in this respect and it goes beyond its strong cultural and symbolic value. In fact, industrial-cultural heritage is able to re-enact people's capability to maintain the culture of the past while looking forward with appropriate and innovative design solutions. This paper focuses on the design of regeneration of the former Philips' electronic industrial area named Strijp S in Eindhoven, the Netherlands. The master plan is pioneer in experimental rules on development areas due to the Crisis and Recovery Act (2010), a new Dutch law in response to development and economical crisis. The authors identify four criteria of analysis in order to show the complexity of this urban transformation and assess the results of this work-in-progress transformation. Moreover, it will discuss the challenges for industrial architecture/heritage when incorporating different objectives of redevelopment and to which extent the local dynamics are linked to the design of reuse. As conclusion, the paper will debate on the comprehensive urban framework, which puts forward sustainable design criteria, sets out principles in temporary and long-term reuse of the old buildings, and on their implication in terms of urban quality of indoor and outdoor spaces.
\end{abstract}

Key words: Urban transformation, industrial heritage, heritage conservation and reuse, creative industry.

\section{Introduction}

This paper aims at the exploration of broader issues related to urban regeneration and reuse through the analysis of the renewed industrial area of Strijp S, former Philips Electronics terrain in Eindhoven, the Netherlands. In turn, this exploration sheds light on the forces at play in changing landscapes of industrial cities. The urban transformation of Strijp S addresses both the local interest in the "selected" reuse of the former industrial building stock and the need to re-create urban interrelationships and urban quality. Moreover, the master plan for Strijp S shows a range of remarkable and inspiring design concepts and features that are able to generate the creative urban quarter. This project strongly supports those concepts

Corresponding author: Babalis Dimitra, assistant professor, research fields: urban design, ecological and sustainable urban regeneration and development, urban renewal and reuse of cultural heritage, sustainable master planning. that include, in every stage of design planning and design choices, the preservation of industrial heritage, its relationship with the urban form, its adaptation into new uses, while allowing the development of new one.

The issues of urban regeneration and creative industry, a term that has influenced urban planning since 1990s as an interpretative key of innovative urban renewal dynamics, are based on emerging styles of living and working [1,2]. The achieved recognition of cultural heritage, both tangible and intangible and of urban landscapes $[3,4]$ should be able to re-enact people's capability to maintain the culture of the past while looking forward with appropriate and innovative design solutions.

Therefore, industrial heritage and heritage management must be considered essential components in the definition of the identity of the context and as instruments of rooting the innovation in local 
community [5].

UNESCO (United Nations Educational, Scientific and Cultural Organization) raised the issue of cultural industries and cultural development and the protection of cultural diversity. This is the basis for understanding cultural activities, goods and services and market and the consequences for integration of culture and creativity in sustainable development and sustainable cooperation [6].

Further, UNESCO studies in the last decade encouraged countries and authorities to recognize creative industries and to prioritize this research field. UNESCO's role has mainly started to develop specific statistics and policies to promote this growing field of research without imposing standards or forcing countries to collect these statistics. Consequently, this mainstreaming has led to a growing body of analysis on the relationship between culture, creative industries and economic development.

However, UNESCO needed to update the FCS (framework for cultural statistics) about cultural activities (developed since 1986), to capture the advanced varied ways of culture. The technological change, in fact, has profoundly revolutionized the way people create and work. The emergency of creative industries as a distinct area of specialization must be further taken into account for local redevelopment and economic activity [7].

Recently, UNESCO's global report on the monitoring of the 2005 convention identifies global trends and challenges and added values integrating culture in sustainable development frameworks [8].

Furthermore, several international charters and legal instruments have recognized the need of redeveloping historic landscapes according to sustainable decision-making, and have given greater emphasis on the active involvement of local community in the protection and management of the cultural heritage [9].

Industrial archaeology has led to a sensitive way of thinking in terms of preservation and conservation but also on the reuse of industrial heritage. In fact, preserving both heritage values and meanings is beneficial to design sensitivity and it welcomes the changes of a place. Thus, including heritage in innovative development schemes becomes a challenging opportunity for city's transformation [10].

There is no doubt that good understanding of former large industrial areas and their key assets can bring to a successful redevelopment. However, the control of the master plan process cannot always guarantee the achievements of good urban results and liveable environments. As a consequence, the established procedures for reaching decision for redevelopment can seriously affect quality of design and assessment of value of cultural heritage.

Urban change, which includes the industrial landscape, is mainly driven by the perspective of reaching new sustainable economic, social dynamics and creative innovation. One of the most critical points is the re-integration of urbanity into the new urban fabric [11]. This highlights how crucial is the implementation of an efficient redevelopment model able to offer and integrate transformation within a potential range of achievements.

The transformation of Strijp S, former Philips' electronic industrial terrain in Eindhoven, is a case in point.

Built between 1915 and 1930, Strijp $\mathrm{S}$ is characterised by impressive industrial buildings for the production process of light bulbs, radio and television appliances. The factory was active until 2000. Afterward, the production moved abroad and Philips' headquarter relocated in Amsterdam: The area of about 27 ha became available to new uses. In 2002, the ground and empty buildings, some of which have the monument status, became property of the Municipality of Eindhoven. Two years later, by establishing an operating agency (Park Strijp Beheer) with a development company (WolkerWessels), the Municipality initiated a highly ambitious process of transformation. It aimed at the regeneration of Strijp S 
as "Creative City" where a mix of workplaces, housing, public services, cultural facilities and inspiring business accommodations would coexist.

Strijp S Project should be considered as one of the most significant examples of urban transformation which well combines the evaluation of the former industrial building stock and the development of new one in order to shape a dynamic and creative urban quarter.

\section{Method and Materials}

This paper seeks to understand how the industrial heritage of Striip S and its transformation has shaped a "different" urban regeneration project than many other cities.

Rather than assessing the general aspects concerning the contribute of this project to the city's life, this paper will investigate the urban regeneration of Strijp $S$ by identifying four criteria of analysis as follows:

- heritage conservation: It refers to the material/immaterial legacy of the site;

- urban development: It concerns the relationship with the existing context;

- creative industry: It is about the search for inspiring spaces for a mix of compatible uses and the goal of creating innovative synergy among different activities.

- new architecture: It regards architectural additions and new buildings proposed by the regeneration plan.

The above-mentioned criteria will show the complexity of this urban transformation and the challenges for industrial architecture/heritage when incorporating different objectives of redevelopment.

In so doing, authors will explore the extent to which local context and dynamics are linked to the design of development. The paper begins by outlining the historical context of Strijp $\mathrm{S}$ and it provides an overview on the structural setting of the site and key buildings that are strong expression of the industrial past. It will follow the analysis of the design of transformation according to the four criteria: heritage conservation, urban development, creative industry and new architectural structures. The paper concludes by assessing how these criteria have informed the "new" Strijp S and how they contribute to our understanding of urban regeneration.

This paper makes use of newspapers, municipal and designers' documents, interviews and web-magazines to supply evidence on the urban regeneration of the area and the way this transformation has been both envisioned and described.

\section{Strijp $S$ in History and Today}

Strijp S is centrally located in the contemporary urban setting of Eindhoven. Originally, it had a peripheral position in the city, but it was never an isolated area: Strijp T and Strijp R were next to it and large labor housing estates surrounded the industrial areas, connecting them to the social fabric of the city.

The halting of raw supply material during WWI (World War I) was the initial reason for the construction of Strijp S. Therefore, to realize a glass factory comprehensive of the entire production system became a necessity.

In a short period of time, the following were realized: the laboratory of physics, the machine factory, the philite factory for the production of bakelite, several structures for the manufacture of metal products of glass, and wave cardboard for the packaging [12].

These activities were located in the monumental buildings of the "forbidden city" as Strijp S was known, due to the restrict access to it. The "white spine", consisting of three white buildings of seven stores, forms the central axis of the area. Dated 1927, 1929 and 1930, respectively, these buildings have a concrete skeleton and, as in the idea of the "daylight-factory", are characterized by large window frames $[13,14]$. In the "White Spine", there were assembled radio appliances and, after WWII (World War II), also television devices. From the first floor 
upwards, massive bridges connect these white buildings to each other, and they are clad in dark-orange steel plates.

The White Spine ends with the Veemgebouw, built during WWII (1942) as a warehouse for radio and later television sets and other Philips products. Contrary to the previous buildings, the Veemgebouw is characterized by facades in red brickwork, tripartite and marked by white lines and a horizontal raster of window frames that emphasize the distinctiveness and monumentality of the building.

Just behind the high white spine, stands the striking building of the "Klokgebouw" named after the huge clock on the tower (Fig. 1). Dated 1929, the "Klokgebouw" is the emblem of Philips (Fig. 2). Designed by the architects Broekert and Bouten from Philips technical department. It is the first building of Strijp $S$ to come into view from the railroad and to be noticed from the highway. This seven stores concrete building is in line with the architecture of the "White Spine", except for its size that is more than double of each of the three buildings of the spine. In fact, it occupies a surface of about $30,000 \mathrm{~m}^{2}$, including a water tower, which is hidden by the clock [12]. The building was used for the production of philite, a special Philips' variant from bakelite.

In the surrounding area of the Klokgebouw are located two small buildings named the "Machinekamer" (engine room) and the "Ketelhuis" (boiler house) used for the generation of compressed air and electricity.

All the monumental buildings described above form the central area of Strijp S, named "Triangle" and it is the main focus in the design of reuse. Slightly apart from the central axis are located the NatLab, laboratory of physics and the Glasgebouw, for the production of light bulbs. The latter is a nine stores building, with highly detailed brickwork façades that is characterized by white pillars high up to the third floor.

The NatLab is the first laboratory of Philips and it

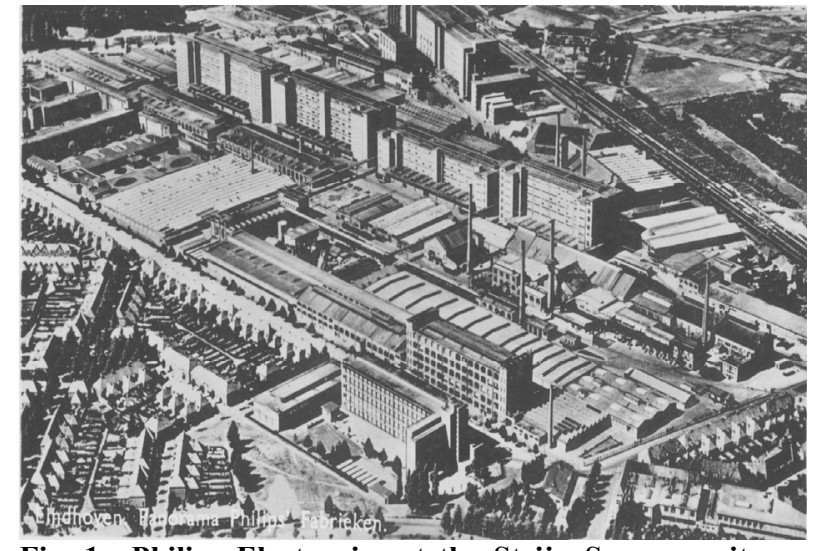

Fig. 1 Philips Electronics at the Strijp $S$ area as it was. Source: Regionaal Historisch Centrum Eindhoven, collection of Poppel, photographer unknown.

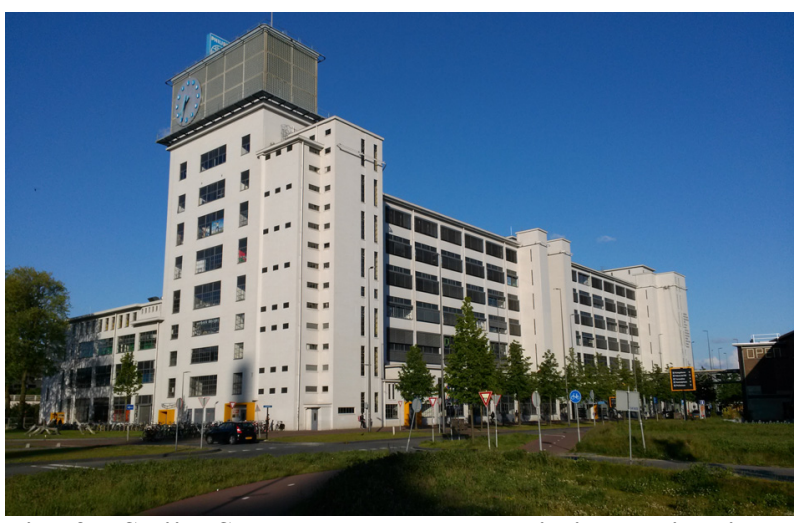

Fig. 2 Strijp S: the Klokgebouw building which is the emblem of Philips Electronics Factory.

Source: photo of M. Piethaan.

belongs to the pavilion-like typology, which was the first example in the Netherlands [15]. Built in 1923, the NatLab appears in strong contrast with the high-white spine buildings, but it also marks as an exception in the typical Philips' industrial units. The protruding auditorium is still the icon of the NatLab and of the City of Eindhoven. The research carried in this laboratory played a central role in the development of Philips [16].

Lastly, in the entire area of Strijp S are still visible the remains of ducts and pipelines, of many colors and sizes, supported by huge steel structures. In the past, they were used to transport fluids and gas across the area, and while connecting and winging the way through the imposing industrial structures, they formed unique "roofs" on the industrial inner 
streets.

\section{Making Redevelopment Plans for Strijp S}

The transformation of Strijp S is among the biggest projects of urban regeneration in Europe: of the current total $330,000 \mathrm{~m}^{2}$ of the area, $120,000 \mathrm{~m}^{2}$ are industrial heritage [17]. In the future, the total surface will be of $440,000 \mathrm{~m}^{2}$ of which:

- 285,000 $\mathrm{m}^{2}$ for living (lofts, dwellings);

- $92,000 \mathrm{~m}^{2}$ for offices;

- 21,000 $\mathrm{m}^{2}$ for retail and trade;

- $10,000 \mathrm{~m}^{2}$ for services;

- $32,000 \mathrm{~m}^{2}$ for others.

In 2002, after the administrative process necessary to change the use of the area in favor of mix of uses, an urban plan proposal (Fig. 3) for the area was made by West 8 Urban Design and Landscape Architecture. This aimed at creating a "new" identity for the site, a "creative heart" for the South of the Netherlands, a round-the-clock living place [18].

The plan proposes a green avenue $60-\mathrm{m}$ wide (named 'Torenallee', tower alley) as a main axis along the white building spine, which is intended as a new icon of the public space in Eindhoven (Fig. 4). Ideally, it connects the green estate of the "Wielewaal" (belonging to Frits Philips, founder of the company), to the inner city. A gate to the site is made through two glass buildings of "original shape". Pavilions of large scale are located in the green field as icons.

The master plan proposes also two parallel urban boulevards as main access for new estates of different density and functions. This new built area will be realized according to the detailed master plan made by Jo Coenen Architects \& Urbanists in 2009 [19]. Accordingly, "boxes" of the size of $52.5 \times 52.5 \mathrm{~m}$ will fit into the orthogonal grid determined by the white building spine and they will be developed as big urban blocks with intimate inner courtyards of different character (open green, labyrinth space, etc.). A $70 \mathrm{~m}$ high tower, which verticality will be in contrast with the horizontality of the block, will mark each box.

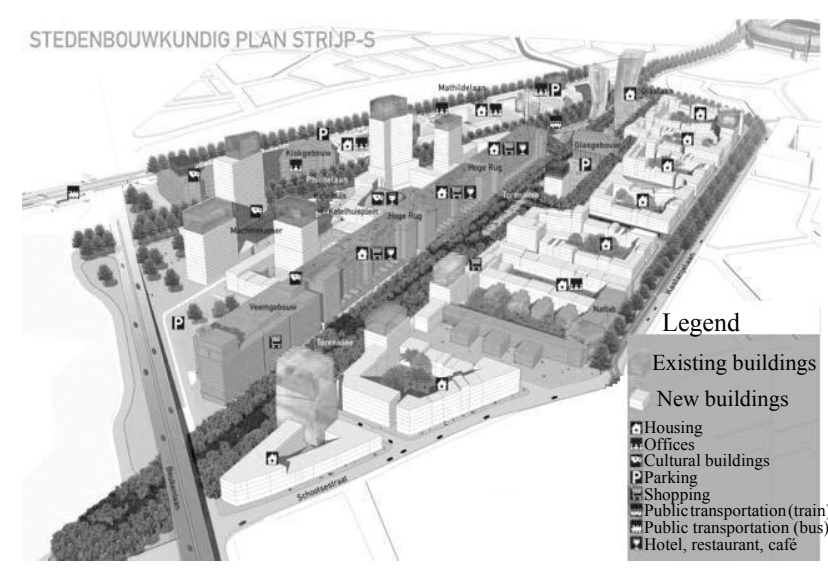

Fig. 3 Strijp $S$ area: the new urban redevelopment plan. Source: http://www.vestigingslocaties.nl/wp-content/uploads/2 014/10/Eindhoven-stedenbouwkundigplan-Strijp-S.jpg.

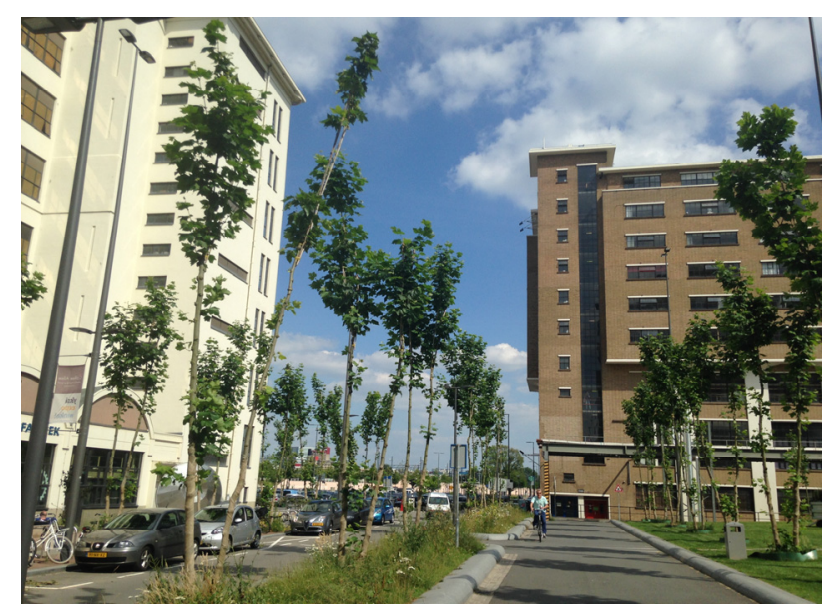

Fig. 4 Strijp S: Torenallee, the green avenue.

Source: photo of D. Babalis.

With concern to the industrial heritage, located in the "Triangle" area, the general design principle focuses on the transformation of the plinths and the roofs of the existing buildings [19]. Both parts will accommodate public functions, while the main body will host lofts and offices of a private character.

This principle applies to the Veemgebouw (project by Caruso St. John), which ground floor will provide the space for a food market (almost 3,000 $\mathrm{m}^{2}$ ) and various retails, while the top floor will be characterized by additional volumes that will host a top-restaurant and a design hotel. The exterior facades will remain unchanged, while the interior spaces will become a sequence of large and different room. 
The transformation of the High Spine is consistent with this general design principle. Named Anton and Gerald Buildings in 2011 (in honor of both co-funder of Philips multinational), these white buildings accommodate public functions at the ground floor: a museum, a gallery, design stores and the area of the "Ontdekfabriek" (Fig. 5), known as the children discovery area [20]. The huge roof landscape is used for gardens and sport activities and it accommodates a variety of energy-efficient appliances. Rental loft spaces fill in the main body of the buildings, and while preserving the interior industrial character, they offer vintage living spaces for a variety of changing users.

Three incisions-passageways were made at the ground floor of the buildings in order to facilitate people's flow from the green avenue to the interior area of the "Triangle". The Klokgebouw is considered the spin-off building for the entire redevelopment of Strijp S [12]. In fact, it plays a significant creative role in the area and it is meant as a business complex with workspaces in various sizes. As a mater of fact, the Klokgebouw is the heart of those well-known yearly events like the Dutch Design Week, or the newly developed STPR Festival (a combination of culture and technology). Contrary to the original plan that intended to host housing and offices, the vast spaces of the Klokgebouw are flexible areas in accommodating live art, dance shows, workshops, exhibitions-festivals, concerts, etc. that local people and cultural tourist can enjoy during the entire year. As for the "Ketelhuis" and the "Machinekamer" buildings, they form the "epicenter" of the northern area of Strijp S and provide a rich combination of public activities (theatre, film, media, cafes, restaurants, etc.) [12].

More specifically, the Ketelhuis building is preserved and reused as place where to deliver a combination of art and food, particularly during special events. The Machinekamer maintains inside the raw industrial character and also the old machines, while a restaurant and fashion design spaces are located at the ground floor. The adjacent square offers a suitable area to artists to play during the Brabant Open Air Music Festival.

The $550 \mathrm{~m}$ long roof of pipelines and ducts, named Leidingstraat is kept as a historical artefact and is an important carrier of the identity of the site [14]. It provides access to the first floors of several buildings. It is an open "catwalk" that connects singular areas for creativity: the High Line Project in New York City is the evident reminder. Aesthetically, this "industrial pergola" is a comfortable green terrace with an original lighting design (by Piet Oudolf, landscape architect). Artistic and temporary interventions show here to what extent is possible to stretch opportunities

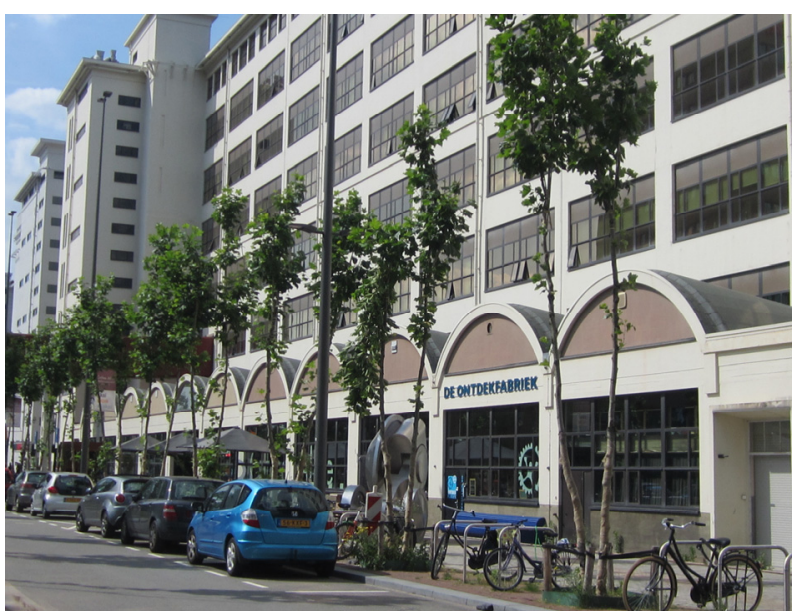

Fig. 5 Strijp S: the Ontdekfabriek in the High Spine. Source: photo of D. Babalis.

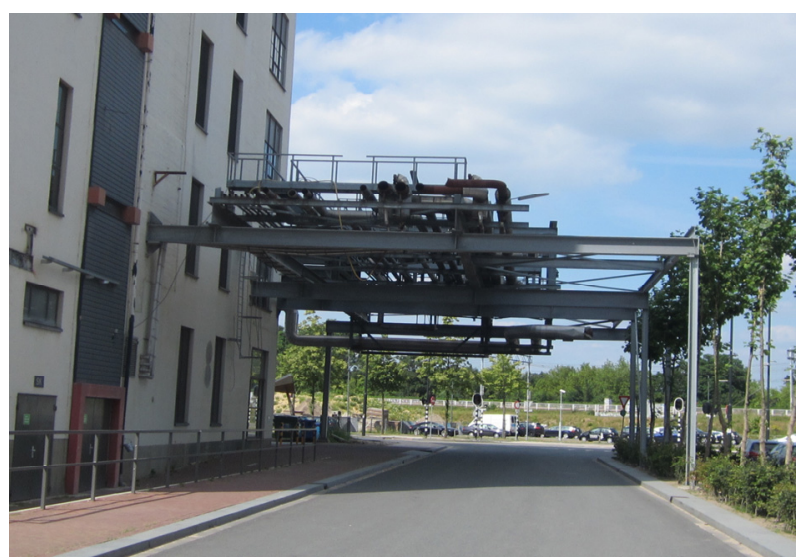

Fig. 6 Strijp S: the roof of pipelines and ducts will be kept as a historical artifact.

Source: photo of D. Babalis. 
for interaction with the surrounding urban environment. In the southern area of Strijp $S$, the design of transformation devotes to housing blocks, forming a transition zone between the industrial sector and the labor housing area close to it. Historical nostalgia emerges in the architectural design of the facades of the housing blocks, which look will remind the old inner city of Eindhoven.

The NatLab, originally destined to a full demolition, will be kept: one wing will be destroyed to make available space for new architecture and it will remain compressed among tall buildings.

The plan of reuse of Strijp S does not only make central the "creative" theme, but it also puts forwards "highly creative" design. In fact, it proposes: a replica of the Philips' pavilion made by Le Corbusier for the World Exhibition in Brussels, in 1958; and "boxes of light" to be scattered on top of the tall buildings as night landmarks, making the whole looking like a video-clip [21]. The intention is to "create" a "new" identity for the site, as it would not have one already. One must really wonder if there is the need for such extreme design.

\section{The New Strijp S: Successes and Failures of the Conversion}

To preserve most of the former industrial buildings was the main intent since the beginning of the design process. ${ }^{1}$ Economical sustainability was not the only reason; definitely cultural heritage gives a strong image to the site and its interaction with the new architecture generates a new form of urbanity, where creative industry, culture and housing can take place. The new mix of uses creates innovative synergy among different activities, attracts different users, while generating a social mix. This is the main aspect of the whole intervention. Moreover, the benefits it provides are multiple: better quality of living, promotion of innovative enterprises and creative

${ }^{1}$ Geuze, A. 2009. Interview in Dings \& Lammers. activities, etc. Thus, original ideas can inspire urban design and formulate practical solutions able to provide appropriate and enjoyable spaces.

In design term, "contrast" is the key word of Strijp S master plan. As stated by Adrian Geuze, ${ }^{2}$ supervisor of the project: "Old and new, hard and soft, formal and informal, concrete and nature will be in contrast, and this will make the area lively and sparkling". Therefore, the new green layer and the small architectural and experimental forms are meant to generate an atmosphere of freedom and contrast that will attract and inspire users of any sort. The latter will experience multiple views generated by the contrast between the clarity-linearity of industrial logistic and the several new routes that deviate here and there, generating visual plays as in the baroque tradition [22].

The regeneration of Strijp $\mathrm{S}$ is work in progress, therefore, the criticism relies on both the assessment of the current results and on the plans for the future development of the area. As in the specified categories of criticism set for the analysis of the project, the following can be seen:

- Creative industry: It concerns mainly functions of public interest, selected in order to foster the theme of innovation and creativity. It is significant that Trudo, the housing corporation that owns part of Strijp S area, explicitly proposed since the beginning of the transformation process, space for creative pioneers and focused on "creative incubator" as identity of the place [12]. Moreover, the company offered temporary rentals (5-year time) to creative pioneers/students for the in-between period occurring to the planned reuse, welcoming combinations and dynamics of a variety of activities and users. Slowly, a synergy among the parties is developing, which includes i.e. collaborative productions for new events at national level. Residential functions have a significant presence in the mix of uses, but the landscape remains still

${ }^{2}$ Ibid. 
industrial. Shortly, the regeneration of Strijp S can be interpreted as a contemporary industrial complex, of a creative character, provided by the mix of uses envisaged by the master plan;

- Urban development plan: The regeneration plan is based on the long-term process of development that suggests a dynamic master plan. It favours a "chessboard play" that gives value to the in-between time and allows adjustments and changes over time. Moreover, the focus is on an integrated urban design where the human scale and the perception and observation by the user have priority on idealistic design plans [23]. The project foresees $440,000 \mathrm{~m}^{2}$ of living, working and service space, of which 120,000 $\mathrm{m}^{2}$ is within the industrial heritage, plus public transportation of guided buses on an electronic pathway;

- Heritage conservation: The monumental size and landmark effect of the existing industrial buildings are enhanced both in the urban and landscape design: the combination between the old and the new has formed an integral part of the planning process. Thanks to the preservation of the industrial historic landscape, the adaptive reuse of the built heritage has determined the key success of the project. Moreover, it is interesting to see how the industrial grid dictated by the high-spine has informed the new urban blocks along the railway line (Fig. 7). However, some drastic interventions must be pointed out: the NatLab has lost its unique characteristic of pavilion and the demolition of some parts of it has broken the sequence of courtyards that were special features of NatLab interior spaces; The same applies for the "Apparatenfabriek", located within the high-white spine, which ground floor is drastically changed in order to host public functions;

- New architecture: Consistently with the principle of "contrast", the new architecture proposes contrasting materials and higher volumes to the existing one.

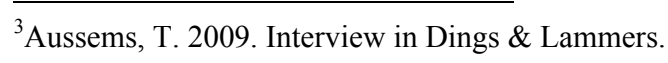

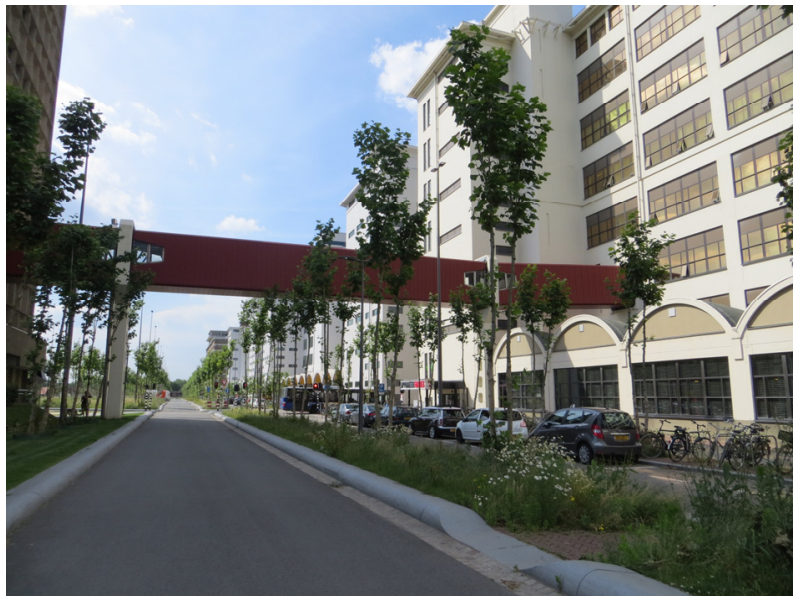

Fig. 7 Strijp S: the Hoge Rug, the High Spine. Source: photo of I. Curulli.

one. Glass is the protagonist material: (1) A glass skin will wrap the two undulating towers that will mark the entrance to the site; (2) Glass boxes will crown the family of towers scattered in the entire area; (3) Glass pavilions (or green houses) will be the icons on the green axis. This abundant glass-lightness will be counterbalanced by brick facades, used for most of the urban blocks. The introduction of new towers will compete in the skyline with the former industrial buildings, which are symbolic landmarks of the industrial past of the local community.

\section{Conclusions}

Strijp S urban regeneration project has brought new life into the City of Eindhoven. The 27 ha former industrial site, with its new mix of uses, is of great potential and has a strong impact on the city. Thanks to the cooperative effort between the municipality and the commercial market, Strijp $\mathrm{S}$ has been able to elaborate a "very gradual phasing, not only physical but also in duration, (...) resulting in a flexible zoning" [12]. In the short term, this approach provides opportunities for temporary use, while in the long-term it gives the possibility to create a vibrant urban environment, with a strong dynamic, that takes into account changes in the demand of residential, creative and leisure sectors. This was the reason for awarding Strijp S Project of the Dutch "Golden 
Phoenix" prize (2013), which is assigned exclusively to projects concerning the existing built environment [24].

Moreover, it is interesting to note that the approach adopted in the planning of Strijp $\mathrm{S}$ was made possible thanks to a new law, named Crisis and Recovery Act (2010) [22]. In fact, Strijp S was one of the first projects to be notified in the area development plans under this law, which allows experimental rules on development areas.

Nowadays, renewal projects of dismissed industrial areas are becoming strategic in the city's management of contemporary cultural heritage. The questions that they might arise are various and numerous: How changing urban pattern can be seen in relationship to the tackling social problems such as fear of isolation and loss of urban identity? Are memory and meaning of former industrial sites valuable resources?

This means that heritage must be interpreted more as cultural heritage than as building restoration. Its significance goes far beyond the preservation of the architectural envelope and it expresses the sense of collective memory and of human work.

In the specific case of Strijp $\mathrm{S}$, the unique perception of tangible and intangible heritage gives a sense in terms of both art and utility. The use of green landscape and lighting in the public realm, in order to highlight both past and present, is also expression of sensitive thinking of art and design (Fig. 8). Art and design is created as an expression of local exploration of a proper creativity and to multiple interpretations. Reuse of old building, together with the design of new ones, already has a traditional collaborative process, and it can create new incentives for a socio-economic system. This is the most obvious conclusion with regards to new buildings as Dutch architecture has always represented the prototype, highly distinctive. Meanwhile, the temporary use of land or buildings during special events can be a great opportunity for creativity and artistic practice.

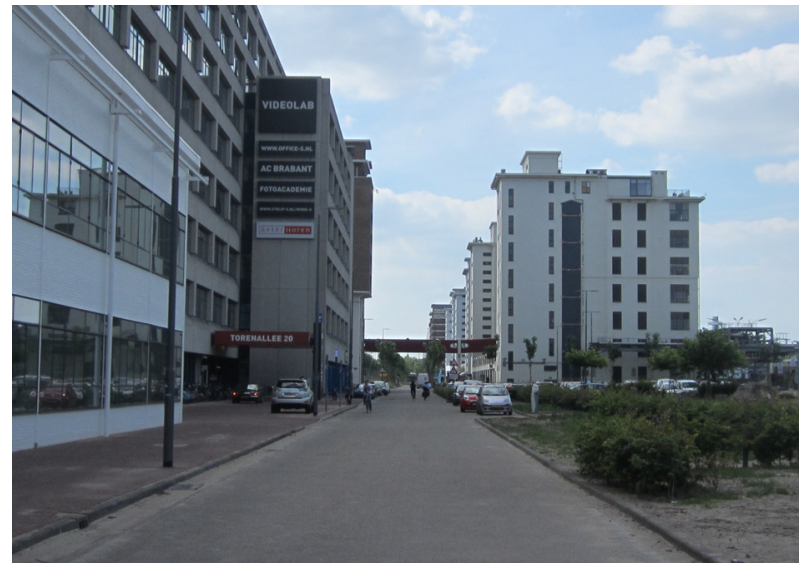

Fig. 8 Strijp S: the main entrance to the creative urban quarter and the High Spine in high back.

Source: photo of D. Babalis.

The nature of this master plan can provide many benefits to everyday life, to market and business activities. The practical experience of living, working and performing in such urban historical environments can bring a valuable, enjoyable and productive activity. These distinctive features have led Strijp S Project into the world of urban regeneration and place making with cultural activities. This may be seen somehow incongruent. Instead, the adopted urban strategy and policies, together with local people's desire to "re-live" into this dismissed area, can create a unique place in the contemporary urban condition.

However, the existence of a cultural neighborhood can be facilitated by a true urban policy, but it cannot be created. This implies that the management of industrial heritage must focus on communicating meanings that are rooted in the community; Thus the sense of place returns and generates an enriched identity together with a sense of contemporary and dynamic community [25].

The regeneration of Strijp $\mathrm{S}$ can be seen as a valuable way to re-shape former industrial environments of strong historic value in order to attract more attention and reactions to its surrounding context, while enhancing current socio-economic improvement. Debates on regeneration issues and practices for a creative response, sometimes, can be further formalized into local authorities behavior. 
The Stijp S urban transformation intended for high level of sustainability, creativity and smartness of a mixed-use redevelopment, looks at creating economic profit and value of the place. Additionally, it tries to re-defines the role of public and private sector in delivering good projects, while sharing short and long terms investment opportunities. From the very beginning, the Municipality of Eindhoven supported those proposals that were critically proposing short term sharing, and with a clear vision for the future.

Beside the statutory decision undertaken by the municipality it is essential to underline that the detailed redevelopment schemes, during all planning process, allowed the designers to promote responsive urban environments, local distinctiveness and collaborative relationship able to fulfill the vision and needs of the local community.

The proposed master plan assesses connectivity towards Eindhoven's City Center allowing an easier urban interaction. On the other hand, the conversion of the old industrial with the new mixed uses, ensured livelihood.

What seems clear in looking to the future is that new forms of urban regeneration of vast former industrial area should emphasize the following:

- planning process that can improve accessibility, movement and connectivity with the existing urban context;

- role of urban design in implementing creative transformation;

- preservation of industrial heritage by re-discover its value through alternative programs in the reuse of old industrial buildings;

- design of new buildings that complement the old one and all together the structure of the regenerated site.

The interest on creative urban regeneration of former industrial areas started from a growing curiosity about good practice redevelopments within industrial contexts of great historic importance. As the findings were based on only one case, it would be beneficial the investigation of additional and significant case studies in order to bring together a more specific issues on urban complexity, master planning process, strategic approaches to sustainability and environmental management and architectural design.

At the same time, the research findings discussed in this paper acknowledge sustainable design criteria in the conversion of old industrial buildings into new uses, on performing smartness of built environment and going deeper into creative industry.

Briefly, some recommendations on planning and master planning of former industrial areas can be given:

- recognition and acceptance of risks in developing projects of transformation;

- responsible sharing of culture and creativity of a place;

- understanding the variety of space qualities that can be delivered after the intervention;

- understanding how the interaction between people and authorities could produce good places to work, live and enjoy daily life.

\section{References}

[1] Fossa, G. 2015. "Creative Industries and the Use of Heritage.” In Industrial Heritage Sites in Transformation: Clash of Discourses, edited by Oevermann, H., and Mieg, H. A. London: Routledge.

[2] Ashworth, G. J., and Turnbridge, J. E. 1999. "Old Cities, New Pasts: Heritage Planning in Selected Cities of Central Europe." Geo Journal 49: 105.

[3] Secretary of State for Foreign and Commonwealth Affairs. 2012. "European Landscape Convention." Stationery Office Limited. Accessed May 20, 2012. https:/www.gov.uk/government/uploads/system/uploads/ attachment_data/file/236096/8413.pdf.

[4] Council of Europe. 2005. "Council of Europe Framework Convention on the Value of Cultural Heritage for Society." Council of Europe. Accessed April 8, 2015 https://rm.coe.int/CoERMPublicCommonSearchServices/ DisplayDCTMContent?documentId=0900001680083746.

[5] Cunningham, S. 2002. "From Cultural to Creative Industries: Theory, Industry and Policy Implications." Special issue, Media International Australia incorporating 
culture and policy. Quarterly Journal of Media Research and Resources: 54-65.

[6] UNESCO (United Nations Educational, Scientific and Cultural Organization). 2005. "Convention on the Protection and Promotion of the Diversity of Cultural Expressions." Accessed February 12, 2016. http://en.unesco.org/creativity/sites/creativity/files/con vention2005_basictext_en.pdf.

[7] UNESCO and Global Alliance Team. 2006. "Understanding Creative Industries Cultural Statistics for Public-Policy." Accessed February 12, 2016. http://portal.unesco.org/culture/en/ev.php-URL_ID=2994 7\&URL_DO=DO_TOPIC\&URL_SECTION $=-465 . \mathrm{htmt}$.

[8] UNESCO. 2015. "Re-shaping Cultural Policies: A Decade Promoting the Diversity of Cultural Expressions for Development." UNESCO. Accessed February 12, 2016. http://unesdoc.unesco.org/images/0024/002428/242 866e.pdf.

[9] Bandarin, F., and Van Oers, R. 2012. The Historic Urban Landscapes, Managing Heritage in an Urban Century. West Sussex: Wiley-Blackwell.

[10] Roberts, P., and Sykes, H., eds. 2005. Urban Regeneration. A Handbook. London: SAGE Publications.

[11] Babalis, D. 2012. Urban Change and Sustainability. Florence: Alinea International Publisher House.

[12] Cerutti, V. 2011. "Klokgebouw Strijp S, Eindhoven, Try to be Different." In Creative Fabrieken. Waardecreatie met Herbestemming van Industriele Erfgoed, edited by Cerutti, V. Utrecht: C2 Publishing.

[13] Geevers, K. 2014. "Stedenbouwkundige Waardestelling van Industrieel Erfgoed." Ph.D. thesis, Technische Universiteit Delft. (in Dutch)

[14] Santen, van J. 2012. "Van Daylight Factory naar Creative Stad. Trasformatie op Strijp S." Rijksdienst voor het Cultureel Herfgoed 1 (January): 1-12. (in Dutch)

[15] De Jong, J. 2006. Gemeente Eindhoven: Cultuurhistorische Analyse Strijp $S$. Eindhoven:
Municipality of Eindhoven. (in Dutch)

[16] Vries, de M. J., and Boersma, F. K. 2006. 80 Years of Research at the Philips Natuurkundig Laboratorium 1914-1994. Amsterdam: Pallas Publications.

[17] Gelinck, S., and Strolenberg, F. 2015. "Strijp S, Eindhoven. Een Stad moet Oonstaan, die kun je Niet Maken." In Rekenen op Herbestemming, edited by Gelinck, S., and Strolenberg, F. Rotterdam: Nai 010 Publishers. (in Dutch)

[18] Park Strijp Beheer. 2009. “"Creative City. Strijp S (Strijp S Brochure.” Park Strijp Beheer. Accessed January 24, 2009. https://www.strijp_s.nl.

[19] Jo Coenen Architects \& Urbanists. 2011. Master Plan. Driehoek Strijp S. Original booklet made for Trudo and identified as document: JO COENEN-090902_stedenbou wkundigplan_driehoek.def.

[20] Graat, G. 2008. Eindhovens Dagblad. Eindhoven: Wegener. (in Dutch)

[21] Assche, van K. 2004. "Hier Wart de Geest van Vernieuwing." Blauwe Kamer 6 (December): 42-9. (in Dutch)

[22] Verschuuren, J. 2010. "The Dutch Crisis and Recovery Act: Economic Recovery or Legal Crisis." Potchefstroom Electronic Law Journal 13 (5): 5/189-25/189. Accessed May 2, 2015. https://pure.uvt.nl/portal/files/1318413/Ver schuuren_Dutch crisis and recovery act 110323 publis hers_immediately.pdf.

[23] Aussem, T. 2014. "Initiatiefnemer." In Rekenen op Herbestemming, edited by Gelinck, S., and Strolenberg, F. Rotterdam: Nai 010 Publishers. (in Dutch)

[24] West 8 Urban Design and Landscape Architecture. 2013. "Strijp-S Wins Prestigious Golden Phoenix Award in Area Transformation." West 8 Urban Design and Landscape Architecture. Accessed May 2, 2015. http://www.west8.nl/en/press_releases/06_june_2013/pdf/.

[25] Cochaine, A. 2007. Understanding Urban Policy. Oxford: Blackwell Publishing. 